\title{
The Relationship between Structural and Content Dimensions of Organization with Crisis Communications Preparedness
}

\author{
Amir Hossein Amirkhani \\ Associate Professor, Payame Nour University, Tehran \\ Ali Reza Saremi \\ PhD Student, Governmental Management, Human Resources \\ Rahman Shahraspi \\ PhD Student, Governmental Management, Human Resources
}

\section{Doi:10.5901/mjss.2016.v7n3s2p54}

\begin{abstract}
The aim of this study was investigation of the relationship between structural and content dimensions of organization with crisis communications preparedness among municipalities of Fars province. At the beginning, we extracted the effective activities in crisis communications preparedness by studying several articles. These activities include: preparation and adjustment of crisis management program, formation of crisis management team, training, and preparation of lists for fast access to the responsible people during the crisis situation and use of warning systems in the organization. A questionnaire was used to measure the attitude of the staff and municipal leaders. We used descriptive and inferential statistics for analyzing the data. In order to analyze the hypothesis we used Pearson's correlation coefficient test and ANOVA test (F). Statistical analysis indicates that there is significant relationship between structural dimensions of organization (Including: formalization, complexity, concentration and process-orientation) and structural content of organization (Including: technology, strategy, organization size and organizational culture) with crisis communications preparedness in municipalities of Fars province.
\end{abstract}

Keywords: Crisis communication preparedness, structural dimensions of organization, Content dimensions of organization, Municipality.

\section{Introduction}

Traditional view towards crisis management believes that crisis management means putting out fire; In other words, crisis managers wait until matters are out of hand and after a desolate state has been reached, they spend effort to limit the losses from the ruin. Yet, now a day this outlook has changed. Based on recent definition, a collection of designs and practical plans for confronting potential future evolutions in organizations need to be organized constantly and directors should think about potential future events and achieve preparedness for facing unpredicted incidents. Therefore, crisis management emphasizes the necessity of regular prediction and preparedness for the group of internal and external events that seriously threaten the fame, profitability and or sustenance of an organization. Even though predicting all problems and events from before is impossible, yet, evidence shows that mishaps and adversities happen because executive directors do not think about unpredictable events. Therefore, organizations frequently for confronting with derangements face high expenditures. These derangements can be decreased with preparedness in the event crisis occurs or even prevent them. Regardless of the kind of crisis, companies need to be on top of things and forewarned at all times such that they can organize a crisis situation and attract attention of leaders to it. This is an important topic in the science of management and organization (Carmeli and Schaubroeck, 2008).

Rabii and Shahghasemi (2006) note that when general capacities of a system such as technology, culture, human resources, structures, ideology, level of resilience and responsiveness are less than the capacity for destruction, vulnerability, weak points, level of involvement of external variables and volume of the crisis, disaster is created. McCarty (2002) considers the predominant characteristics of every crisis a mix of three elements of threat or opportunity, shortness of existing time and level of psychological stress imparted. Crisis situations endanger the goals of the decision making unit, limit the time for responding to changes and surprises decision makers. It can be stated that people across the world every day encounter events that lead to death, harm, property damage and disorder in daily activities. Some of 
these incidents such as flooding, earthquake, hurricane, tsunami, drought ... are natural and some other such as industrial, nuclear, computer, transportation, war incidents are unnatural and human created. These factors have undesired side effects on individuals, groups, organizations, societies and even nations. The country of Iran is not exclusion to this principle, such that we are witness to geological, atmospheric and environmental changes and occurrence of crises as a result of them has been barrier to the trend towards growth of economic, industrial and agricultural growth. Due to special weather conditions, geology and geographic location, among 43 natural disasters occurring in the world, near 31 has repeatedly been in Iran. Therefore, Iran is considered one of 43 vulnerable countries in the world. As a result, appropriate preparedness and planning in optimal resource management for prevention of crisis and preparedness in case it happens is an unavoidable necessity for the country's crisis management. One of the organs that can play determining role in the four stages of a crisis is the city department. Considering the importance of the issue, the department of state in guideline numbered 17189 dated May 5, 2015 issued the necessity of formation of army forces for crisis management in the city departments. The main purpose of preparation of this guideline was creation of an organizational structure for implementation of the legal duties of city departments in the four stages of crisis management (prediction and prevention, preparedness, confrontation and renovation and rehabilitation) and inter and intra organizational collaboration and interaction with other relevant organizations and systems in a way that secure and appropriate conditions for livelihood of citizens is created and fundamental values of the city are protected.

For preparedness in the event crisis happens, consideration should be given to structural and content dimension and the proportionality between the two organizational dimensions with organizational structure and also related activities to crisis. Structural and content dimensions can help flow of information. Attention to these dimensions can lead to communication between main organizational pillars, coordination between their activities, intra organizational communications and necessary preparedness for confronting with threats and use of opportunities. Considering the mentioned cases, this research is specifically focused on preparedness of crisis communications in the city departments of the Fars Province and evaluates key structural and content variables of the organization in relation with its communicative preparedness in the event a crisis happens. With consideration of the issues mentioned above, the researchers sought to respond to the following questions:

1) Is there a correlation between the organization's structural dimensions (complexity, formalization, concentration and process orientation) with communications preparedness for crisis in the city departments of the Fars Province?

2) Is there a correlation between organization's content dimensions (technology, size, strategy and organizational culture) with communications preparedness for crisis in the city departments of the Fars Province?

\section{The Theoretical Framework of the Research}

\subsection{Definition of crisis, crisis management and communications preparedness for crisis}

In the opinion of the thoughtful and experts in various sciences such as management, «crisis» has different meanings and functions. Therefore, achieving a specific and unified definition in this regard is difficult and maybe impossible. The important point is that any definition of crisis is relative and on the one hand, the concept of crisis finds relevance in relation with and companionship with concepts such as security, power, national interests, goals, threats and .... Crisis is a dynamic situation that its consequences are severe disorder in order and balance of a system. Design and application of an organizational system that has the ability to face pathologic disasters is considered a major managerial challenge (Carmeli, 2008: 180). In Table 1, some common definitions used in the context of crisis and its management will be mentioned.

Table 1: Common definitions of crisis and crisis management

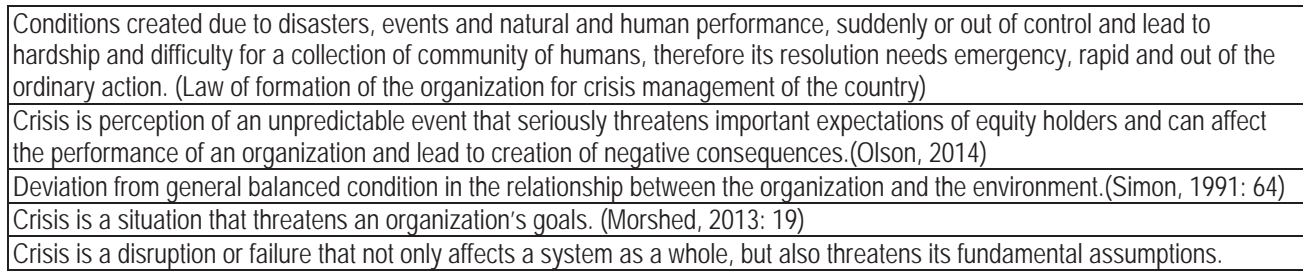




\begin{tabular}{|l|}
\hline (Barnett et al, 2000) \\
\hline Crisis management is the logical process of confronting it for its containment and returning the crisis situation back to normal \\
and protecting and providing fundamental values and interests that have been threatened due to the crisis. (Tajik, 2010: 83 ) \\
\hline Crisis management is creation of preparedness and provision of necessary arrangements and facilitations for facing with crisis \\
or minimizing its destructive effects. (Ahanchi, 1997: 8)
\end{tabular}

Crisis management has four fundamental pillars: preparedness, decreased damages, emergency reaction and renovation. Preparedness is all operations and actions that enable governments, communities and individuals to rapidly and efficiently react at times of crisis occurrence. Preparing actions in total include preparation of a plan for encountering the crisis, precise estimation of resources and also educating the personnel. This stage includes collection of information, research, planning, and creation of managerial structures, teaching, resource provision, practice and maneuvering (Esmalili, 2009: 8). Sikich (2004) believes that crisis communications preparedness refers to all activities that are performed before occurrence of the disaster for preventing, responding and decreasing its harmful effects. Based on this view point, preparedness includes four aspects of preparation and prevention, identification of crisis, responding to existing needs for reduction of the effects of the crisis and improvement of the situation and renovation. In other words, crisis communications management includes planning and implementation of activities that enable the organization to place people abreast of real events. Five key sets of activities are applied in relation with preparedness of organizations for facing disaster which have been presented in Table 2 .

Table 2: Five key sets related to crisis communications preparedness

\begin{tabular}{|l|l|}
\hline Title & Description \\
\hline $\begin{array}{l}\text { Presence of a compiled plan for } \\
\text { probable crises }\end{array}$ & $\begin{array}{l}\text { Formulation and up to dating plans at specified intervals. It is necessary that during crisis the } \\
\text { plans are placed in the hands of responsive persons. (Penrose, 2000, Caponigro, 2000) }\end{array}$ \\
\hline Tactical preparedness & $\begin{array}{l}\text { Tactical elements are key activities such as determination of the crisis team, selection of a } \\
\text { spokesperson, appointment, teaching, preparation of an emergency website, planning for } \\
\text { equipment and critical instruments at time of crisis, yearly budget and .... (Borda et al, 2004) }\end{array}$ \\
\hline $\begin{array}{l}\text { Education } \\
\begin{array}{l}\text { Preparation and up to dating of a } \\
\text { checklist for emergency contact with } \\
\text { those responsible for crisis management }\end{array}\end{array}$ & $\begin{array}{l}\text { Ability to access personnel, media and other benefactors and also useful communicational } \\
\text { information at the time of crisis. These matters should be up to dated at specific intervals for } \\
\text { better response (Heath \& Millar, 2004; Copenigro, 2000) }\end{array}$ \\
\hline Warning systems & $\begin{array}{l}\text { Regular supervision and search, preliminary and systematic planning for the environment in } \\
\text { case of probable events, identification of effective disasters on the organization and } \\
\text { determination of methods of response. (Campbell, 1999) }\end{array}$ \\
\hline
\end{tabular}

\section{Organizational Dimensions, Crisis Communications Preparedness and Development of Research Hypotheses}

Robbins (2009) considers two dimensions for an organization: structural and content. Structural dimensions represent an organization's internal characteristics. They provide a basis by which organizations can be evaluated and compared with each other. Daffet (2007) believes that content dimensions are representative of the entire organization. They represent the organizations status and influence structural dimensions. For understanding an organization, both the structural and content dimensions are required. Organizational structure is the system of relations that have formed unofficially and ratified formally and govern over the activities of individuals who are dependent on each other for achievement of common objectives (Rezaian, 2007). Robbins (2009) believes that organizational structure has the elements of complexity, formalization and concentration. Yet, these cases are not global. Daffet (2007) has mentioned eight structural dimensions and at another place, Robbins (2009) increases these dimensions to 11 cases. Content dimensions include size, organizational strategy, culture, technology and the environment (Daffet. 2007).

Daffet (2007) notes that formalization shows the limit that the roles of employees are defined based on official documents and certificates. Therefore, formalization refers to the standardization of the organization's activity. Robbins (2009) notes that under such conditions, employees are expected to constantly use set guidelines with specific methods which lead to predetermined results. In occupations which do not need much skill and are frequently simple and repetitive, there is more possibility for formalization. Yet, in professional occupations, this possibility does not exist much and freedom of action of directors needs to increase traversing through the organizational hierarchy (Robbins, 2009). Mirsepasi and Goudarzvand Chegini (2003) in their evaluation in the city department of the Guilan Province have reached the conclusion that in small cities, formalization is at a very low level and in midsized and large cities it is at a high level. 


\subsection{First Hypothesis: There is positive and meaningful correlation between formalization with communications preparedness for crisis.}

Daffet (2009) notes that humans are in an era where complexity is an inseparable component. The concept of complexity can refer to inside the organization or in relation with the environment the organization faces. By intra organizational complexity, we mean number of tasks or minor systems which exist in an organization. Complexity refers to specialists and professional activities as well as the length of professional training of employees. Complexity has three dimensions, vertical, horizontal and spacial or geographic regional. By vertical complexity, we refer to levels at which hierarchy of discretions exist (Robbins, 2007). Daffet (2009) considers horizontal complexity to be the number of job titles or circles that are distributed in the organization in a horizontal manner. Spacial complexity refers to geographic distribution of organizational units. Nafari and Omidfard (2003) in their research in the deputy of expenses section of the office of economy and treasury has reached the conclusion that organizational complexity and enablement of employees have reverse correlation. Mirsepasi and Goudarzvand Chegini (2003) in their evaluation of the city departments of the Guilan Province have reached the conclusion that in small, medium sized and large cities, complexity is very low, low and high respectively.

\subsection{Second Hypothesis: Meaningful difference exists between organizational complexity and crisis communications preparedness.}

Daffet (2009) has noted that concentration refers to the level of focus of decision making in one point in the organization. When decisions are made at a high level in the organization, the firm is called focused. When decisions are delegated to lower levels of the organization, it is called unfocused. Marra has noted that for establishment of wide spread relationships at times of crisis, we need a culture and philosophy of organizational communications. This philosophy can be realized with delegation of independence and freedom of action to the public relations section (Marra, 2004, 320). Open relations environments and exchange oriented leadership increases the level of confidence and trust and strengthens delegation of duties (Engel, 1983, 345). Abebe and Hurt (2015) have shown in their research that organizational crises significantly affects the relationship between average level of cognitive disagreement and perception of the quality of strategic decision making. They also showed that level of organizational crisis influences the relationship between emotional disagreement and quality of decision making by the senior managerial team. Nafari and Omidfar (2003) have confirmed that inverse correlation exists between concentration and empowerment. In other words, with decreased concentration and movement towards flat structures and lack of focus in decision making lead to increased empowerment and proportionate increased preparedness in face of dangers and disasters. Mirsepasi and Goudarzvand Ghegini (2003) in their evaluation in the city departments of the Guilan Province have reached the conclusion that in small cities, focus is at a very high level and in moderate sized and large cities, focus is at a low level. Conrad and Pool (2002) and Cloudman and Hallahan (2006) have reached the conclusion that with delegation of power, organization's communications preparedness in face of a crisis increases. Nouri (2011) in his research has reached the conclusion that with delegation of power, organization's communications preparedness increases in face of crisis.

\subsection{Third Hypothesis: Positive and meaningful relationship exists between organizational concentration and crisis communications preparedness.}

Process orientation refers to the level of structure in the processes and activities in the organization. Overall, process orientation is related with design and improvement of standardized flows with the purpose of facilitation of actions and performance of duties (Nilson, 1998). Process oriented firms follow special traditions and customs. They have a structural hierarchy and face less risks and threats compared to organizations which have no emphasis on processes. For this reason, organizations with directed processes follow procedures such as cultural guidance which is the necessary and natural condition for preparedness in face of crisis. In contrast, organizations that have less directed processes, due to flat managerial structure, can make decisions more rapidly and be more vulnerable to risks (Goodman, 1998). The research by Cloudman and Hallahan (2006) has confirmed a positive correlation between process orientations with preparedness in face of crisis. 


\subsection{Fourth Hypothesis: Positive and meaningful correlation exists between process orientation with crisis communications preparedness.}

Robbins (2009) notes that with regards to how the size of an organization is defined and determined agreement does not exist between researchers. Yet, in most studies, the size of an organization is defined as follows: the largeness of a firm which is determined by the number of employees and personnel. Crisis preparation has direct correlation with firm size.

In his opinion, the highest level of preparedness perceived is related to organizations with more than 500 employees; while, the least amount of preparedness involves firms that have number of employees between 20-99 individuals (Marra, 2004: 465). The results of research by Guth (1995) showed a strong correlation between firm size and crisis experience.

In other words, with increased size of an organization, level of crisis occurrence in the organization increases. The research by Cloudman and Hallahan (2006) and Nouri (2011) showed that correlation exists between the size of an organization and preparedness in face of crisis.

\subsection{Fifth Hypothesis: Meaningful difference exists between organization sizes with crisis communications preparedness.}

Robbins (2009) notes that technology refers to information, equipment, techniques and necessary processes that transform inputs into outputs. Technology is applicable in any kind of organization including service or production companies. With expansion of communications under the web, most service organizations plan their activities dependent on digital services based on digital technology and using the web. This form of activity provides the necessary platforms for collaboration, communication, search of information, persistent relations with customers or clients and .... Guntzburger and Pauchant (2014) in their article titled «Complexity and management of ethical crisis: systematic analysis of the Fukushima nuclear disaster» have concluded that beyond appearing simplicity of sudden natural disasters, a complex network of legal, cultural, technological paradigms and defense mechanisms of lack of organizational and personal ethical participation - which has been structured in the context of this crisis- in turn permits the occurrence of this tragedy (Guntzburger, Pauchant, 2014: 390-391).

\subsection{Sixth Hypothesis: Positive and meaningful correlation exists between technology and crisis communications preparedness.}

Robbins (2009) in many cases uses the term strategy and goal as synonyms. Peter Darker has noted that whatever the kind of structure selected for an organization, it must be appropriate with the firm's objectives. Strategy can be defined as the process of determination of fundamental long term purposes, adoption of method of work and allocation of necessary resources for realization of these goals. Strategic management based on «must's» advances the organization towards its overall goals. Yet, crisis management with focus on the «must not's» smoothens the path of traverse. Therefore, the method an organization's higher management considers for confrontation with dishevelment and crises can be an important part of the firm's strategy (Johnson, and Scholes, 1998). Drabek (2003) believes that relationship exists between crisis planning groups and an organizations potential for resilience. Hosseini and Damnabi Asl (2013) in evaluation of the level of effect of strategic management on the quality of crisis management operations in the rail transportation industries of the country reached the conclusion that companies in which strategic management has been established and strategic management processes for crisis handling has been organized show better quality of crisis management operations. Ritchie (2004) and Preble (1997) emphasize the necessity for integration and combination of the stages of formulation, implementation, control and evaluation of the process of strategic management with the stages of formulation, implementation, evaluation and feedback of crisis management.

\subsection{Seventh Hypothesis: Positive and meaningful correlation exists between strategy and crisis communications preparedness.}

With a look at successful organizations, one can become aware of key and common factors between them which build the context for and may be the main factor of their success. Results of studies of researchers such as Edgar Shine, Williams and Dobson, Peters and Waterman and others support the factor of organizational culture as one of the success factors in organizations (Ritchie, 2004:675). Goby and Nickerson (2014) in their article titled «Effect of culture on 
interpretation of organizational crisis: perceptions of crisis in Dubai» state that for organizational crisis communications to be effective, it must emanate from deep awareness of cultural issues and that how stock holders react to various kinds of disasters. In their evaluation, they have stated that the special cultural characteristics of the United Arab Emirates influence perceptions of crisis. In their opinion, cultural traits such as need for avoidance of the definite and direction towards group priorities relative to individual ones is influential on the way organizational crisis is perceived. Yazdi (2007) with attention to the cultural dimensions of Hofsted reasons that the score of Iran in the dimension of organizational power distance and proportionate to crisis related firms is determined by a focused form and personal relations. In the dimension of individual orientation, the people of Iran have a high index. Therefore, people at times of crisis occurrence prefer relatives and family over others which can be harmful in times of crises. He notes that the society of Iran pays more attention to feminine values and spirits and quality of life and relations in organizations and masculine spirits such as courage, bravery and ... which are important at times of crisis are less witnessed. Additionally, at the end, he notes that firms should decrease avoidance of doubt.

\subsection{Eighth Hypothesis: Positive and meaningful correlation exists between organizational culture with crisis communications preparedness.}

Diagram 1: Conceptual model of the research

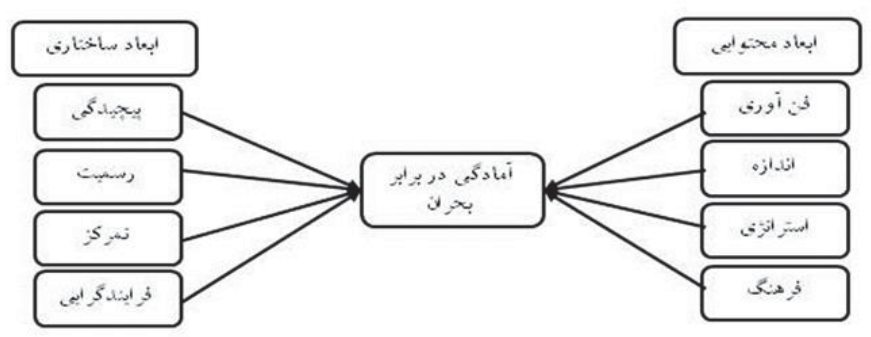

\section{Methodology}

This research was applied in purpose and in quality and method was among descriptive-survey researches.

\subsection{Statistical population and method of sampling}

This research in purpose was applied and regarding method since it evaluates the relationship between variables, it was correlational. Statistical population of this research consisted of directors and employees of city departments of the Fars Province (including men and women). Using the Cochrane formula 324 individuals were estimated as sample size. Considering the width and distribution of the statistical population, cluster sampling was performed in this study. Initially, the city departments of the Fars Province were divided into five geographic regions north, south, east, west and center and next the share of each region was determined for sampling. Ultimately, with the help of Excel software, from among the regions, 25 city departments were selected as representative of the regions.

For evaluation of the first, third, fourth, sixth and seventh hypotheses, questionnaire was used which was scored based on a five-point interval Likert scale (code one was disagree very much and code five was completely agree). For evaluation of formalism and concentration, Robbins's standard questionnaire was used. It should be noted that for evaluation of formalism, the researcher added 4 items to the standard questionnaire. For evaluation of process orientation and crisis communications preparedness, the standard questionnaire of Nouri, organizational culture, Sushkin's organizational culture questionnaire (15 items) and for evaluation of technology and strategy, researcher prepared questionnaire were used.

For evaluation of the second hypothesis based on three dimensions of complexity (horizontal, vertical and geographic region), the city departments were divided into low, medium and high complexity. For this division, factors such as education level, distribution of employees in various buildings, communication levels and various geographic locations were used. Ultimately for evaluation of the fifth hypothesis based on the number of personnel, the city departments were divided into three groups of size small (under 20 individuals personnel), medium size (between 21 to 
100 individuals personnel) and large size (above 100 individuals personnel).

5-2- Validity and reliability of the questionnaire

In this research for evaluation of the validity of the questionnaire, external validity was used such that the questionnaire was distributed among experts and professors in the domain and their opinion was sought regarding the items. Ultimately, they confirmed the questionnaires with agreement of all votes. For determination of reliability, the Cronbach's alpha coefficient was used. The value for the Cronbach's alpha for each of the scales is shown in Table 1.

Table 1: Cronbach's alpha level for each of the research variables

\begin{tabular}{|c|l|c|c|}
\hline Row & Scale & Number of items & Cronbach's alpha \\
\hline 1 & Formalism & 10 & $0 / 87$ \\
\hline 2 & Concentration & 6 & $0 / 70$ \\
\hline 3 & Process-orientation & 6 & $0 / 73$ \\
\hline 4 & Technology & 9 & $0 / 75$ \\
\hline 5 & Strategy & 10 & $0 / 82$ \\
\hline 6 & Organizational culture & 15 & $0 / 71$ \\
\hline 7 & Crisis communications preparedness & 31 & $0 / 75$ \\
\hline
\end{tabular}

\section{Data Analysis}

For evaluation of the research hypotheses, Pearson's correlation coefficient and one sided analysis of variance ( $F$ test) were used. Considering Table 2, the values of sig=0/00 was obtained for the first, third, fourth, seventh and eighth hypotheses and the values of sig $=0 / 001$ was obtained for the sixth hypothesis. Since sig<0/01, therefore the hypotheses were confirmed at a confidence level of 0/99. It should be noted that for the third hypothesis (correlation between concentration and crisis communications preparedness) is inverse. In other words, delegation of discretion and lack of concentration increases crisis communications preparedness. The degree of correlation in the sixth hypothesis (correlation between technology and crisis communications preparedness) is weak.

Table 2: Evaluation of research hypotheses

\begin{tabular}{|c|c|c|c|c|c|}
\hline \multicolumn{2}{|c|}{ Variable } & Coefficient & Crisis preparedness & Acceptance of the hypothesis & Direction of correlation \\
\hline \multirow{6}{*}{ Structural dimension } & \multirow[t]{2}{*}{ Formalization } & Pearson's correlation & $0 / 667$ & \multirow{2}{*}{ Acceptance } & \multirow{2}{*}{ Direct } \\
\hline & & Sig. (2-tailed) & $0 / 00$ & & \\
\hline & \multirow[t]{2}{*}{ Concentration } & Pearson's correlation & $-0 / 428$ & \multirow{2}{*}{ Acceptance } & \multirow{2}{*}{ Inverse } \\
\hline & & Sig. (2-tailed) & $0 / 00$ & & \\
\hline & \multirow[t]{2}{*}{ Process orientation } & Pearson's correlation & $0 / 667$ & \multirow{2}{*}{ Acceptance } & \multirow{2}{*}{ Direct } \\
\hline & & Sig. (2-tailed) & $0 / 00$ & & \\
\hline \multirow{6}{*}{ Content dimension } & \multirow[t]{2}{*}{ Technology } & Pearson's correlation & $0 / 184$ & \multirow{2}{*}{ Acceptance } & \multirow{2}{*}{ Direct } \\
\hline & & Sig. (2-tailed) & 0/001 & & \\
\hline & \multirow[t]{2}{*}{ Strategy } & Pearson's correlation & $0 / 829$ & \multirow{2}{*}{ Acceptance } & \multirow{2}{*}{ Direct } \\
\hline & & Sig. (2-tailed) & $0 / 00$ & & \\
\hline & \multirow[t]{2}{*}{ Organizational culture } & Pearson's correlation & $0 / 546$ & \multirow{2}{*}{ Acceptance } & \multirow{2}{*}{ Direct } \\
\hline & & Sig. (2-tailed) & $0 / 00$ & & \\
\hline
\end{tabular}

For evaluation of the second hypothesis, based on three factors of number of specialists and levels of organizational activities, training sessions completed and geographic distribution of the city departments in various regions (for example, the city department of Shiraz has regions), the degree of complexity of the city departments were divided to low, moderate and high and subsequently, it was analyzed with the use of one sided analysis of variance. Considering the high value for $F(1 / 467)$ and low value for Sig (0/236), with a confidence level of $95 \%$, it can be concluded that meaningful difference exists between the city departments regarding level of complexity (low, moderate, high). Therefore, organization's complexity affects the level of crisis communications preparedness.

Table 3: Correlation between organization's complexities with crisis communications preparedness

\begin{tabular}{|l|c|c|c|c|c|c|}
\hline Variable & \multicolumn{2}{|c|}{ Organizational complexity } & \multirow{2}{*}{ Degrees of freedom } & \multirow{2}{*}{$\mathrm{F}$} & Significance level \\
\cline { 2 - 7 } & Low & Medium & High & & \\
\hline Crisis communications preparedness & 81 & 18 & 1 & 2 & $1 / 467$ & $0 / 236$ \\
\hline
\end{tabular}


Among variables that are influential on the size of the organization is number of personnel. In this manuscript, considering the numbers of personnel, the city departments of the Fars Province were divided into less than 20 individuals, between 21 to 100 individuals, and above 100 individuals and subsequently, they were analyzed using one sided analysis of variance. Considering the high value for $F(0 / 85)$ and low value for Sig (0/431), in a 95\% confidence interval, it can be concluded that organization size is effective on crisis communications preparedness.

Table 4: Correlation between organization's size and crisis communications preparedness

\begin{tabular}{|l|c|c|c|c|c|c|}
\hline Variable & \multicolumn{3}{|c|}{ Organizational size } & Degrees of & $\mathrm{F}$ & $\begin{array}{c}\text { Significance } \\
\text { level }\end{array}$ \\
\cline { 2 - 7 } & $\begin{array}{c}\text { Less than } 20 \\
\text { individuals }\end{array}$ & $\begin{array}{c}20 \text { to } 100 \\
\text { individuals }\end{array}$ & $\begin{array}{c}\text { More than } 100 \\
\text { individuals }\end{array}$ & & & $0 / 431$ \\
\hline Crisis communications preparedness & 74 & 26 & 4 & 2 & $0 / 850$ & $0 / 41$ \\
\hline
\end{tabular}

\section{Discussion and Conclusion}

In this research, it was endeavored to evaluate the relationship between structural and content dimensions of an organization with crisis communications preparedness in the city departments of the Fars Province. Considering the analysis performed, the following suggestions are made in line with the results obtained.

In the first hypothesis, we showed that with increased formalization, crisis communications preparedness increases. Marsh and Robbins have argued that the first step in facing with crisis is formation of groups and putting details into written. The results of this research agree with the study by Kaywood and Stocker (1393). Presence of a compiled plan for probable crises can lead to increased preparedness in confronting them. This plan can include formulation of laws, procedures and guidelines, definition of personal and group role requirements for prevention of disagreement and ambiguity of role, teaching and selection with the purpose of concordance between applicants of jobs and activities under consideration and also defining customs for organization of traditions and behavioral principles for the individuals in the firm.

The second hypothesis shows that meaningful difference exists between city departments with less, medium and more complexity with crisis communications preparedness. As mentioned, Mirsepasi and Goudarzvand Chegini (2003) in their research reached the conclusion that structural complexity in small, medium and large cities is very low, low and very high respectively. It is suggested that principles of coordination of crisis communications management in small cities is performed with direct supervision. In small towns, because there are no extraneous layers in the organization's structure, responsibility of individuals is clear and firm members can comfortably become informed of the company's mission. Therefore, they can easily become aware of the activities and roles of each of the individuals in crisis communications management. Considering the increased complexity in larger cities and that for accurate decision making, there is need for data, information, possibility of their processing and analysis and presence of distinct units named crisis management units is a necessity. With formation of such a unit and standardization of procedures and also delegation of power to skilled city specialists in the context of crisis management, it can be expected that before occurrence of crisis, more preparedness for facing it will be created. This unit can at the time of crisis also prepare the city collection for rapid reaction towards disaster and environmental changes.

Considering the third hypothesis, inverse correlation exists between organizational concentration and crisis communications preparedness. As Marra (2004) argued in his research, for establishment of wide spread communications at times of crisis, we need a culture and philosophy of organizational communications. This philosophy will be achieved by providing independence and freedom of action for the section on public relations. The result of this hypothesis agrees with the research by Nafari and Omidfar (2010) in the context of empowerment of employees.

In other words, movement towards lack of concentration of decision makings leads to increased empowerment and proportionately increased preparedness in face of dangers and disasters. Consequently, it appears that development of personal responsibilities in relation with delegation of power will be useful both for the personnel and for the organization. Providing people with opportunity for growth and blossoming will help them take advantage of increased capabilities and abilities for realization of the objectives of the organization. Additionally, delegation of power with strengthening of group collaboration, individual evolution and prevention of wastage of time by directors leads to more rapid response to unpredictable events. This result agrees with research by Nouri (2011), Conrad and Pool (2002), Cloudman and Hallahan (2006) and Hurt and Abebe (2015).

With consideration of the fourth hypothesis, with increased scores of process orientation, crisis communications preparedness also increases. This supports a direct relationship between these two variables and agrees with the 
research of Goodman (1998) and Cloudman and Hallahan (2006). Process orientation is a method in which main activities of an organization are axial and activities that do not create value are omitted. In process oriented firms, individuals are considered self-autonomous and having creativity and more professional knowledge. Additionally, process orientation resolves the problem with slowness and lack of resilience of an organization, which is one of the important reasons for failure of crisis managers. Therefore, considering the results of the research, it is suggested that for increased preparedness at times of crisis, activities are identified and modeled as much as possible.

In the fifth hypothesis, it was shown that between organizational size and crisis communications preparedness meaningful difference exits. This agrees with the research by Fuller and colleagues (2004), Jayne (2010), Cloudman and Hallahan (2006), Guth (1995) and Nouri (2011). It can be argued that even though with increased size of an organization the probability of occurrence of crisis increases in an organization, yet, crisis communications preparedness also increases proportionately. Some organizational characteristics such as specialty orientation, planning, division of work in large companies is a lot better and based more on principle. On the other hand, larger companies due to having more financial resources can more easily invest in new and more progressed technology. Additionally, access of larger organizations to specialists in various domains is higher. The collection of these factors has led larger organizations to have more preparedness when faced with disaster.

Results of the sixth hypothesis show that correlation exists between technology and preparedness in face of crisis. It can be argued that for directors and specialists in crisis management to be able to achieve determined goals regarding crisis communications, before anything, they need a series of checklists, instruments and various facilities the most critical one of them being access to information and information and communication systems that are stable, up to date, comprehensive, precise and cohesive so they can immediately and timely take advantage of them in all stages of crisis management. Warning systems can in time receive signs, symbols and dangers and evaluate them and present them for crisis management. With consideration of the weak correlation obtained between technology and crisis communications preparedness, it is appropriate that more research is performed in this area.

The highest correlation was observed between strategy and crisis communications preparedness. This has been shown in the seventh hypothesis. It is necessary that disaster strategy is incorporated in organizational strategy and plans. If directors instead of attention to operational and short term plans look with a more long term view towards crisis management and consider more long term horizons in their thoughts, the possibility for success will increase. This shows that crisis management, preventive actions and preparedness in face of disaster and strategic organizational management have a potential power of synergism. The findings of this hypothesis agree with the research by Drabeck (2003), Damnabi Asl (2013), Ritchie (2004) and Preble (1997).

In the eighth hypothesis, we concluded that positive and meaningful correlation exists between organizational culture and crisis communications preparedness. Undoubtedly, the cultural role of a complex is very important in implementation of managerial policies and without consideration of its role, we will never be able to reach fundamental success in all grounds. In crisis communications management, culture can act like a social control system and influence the behaviors and outlook of employees by way of values and opinions that exist in the organization. Values and beliefs such as ability to adapt with the environment, skill in coping and agreement over complex issues and various outlooks, ability for strategic direction taking and acceptance of the firm's mission and goals, hard working organizational culture, process oriented organizational culture, team oriented organizational culture and ... can significantly help in creation of crisis communications preparedness. The result of this hypothesis agrees with the research by Goby and Nickerson (2014).

Organizational communications is among important factors in decreasing disasters in firms. It is suggested that city departments select an organizational structure which is compatible with their content and structural dimensions. Subsequently, with attention to this structure (generally a simple structure for small city departments, sectional structure for medium city departments and matrix structure for large city departments), they can define their role in crisis communications management. In medium and large city departments, with formation of committees and crisis army forces in organizational structure, important step can be taken in planning, determination of primary, short term and long term goals, documentation and presentation of documents, tactical preparedness and implementation of maneuvers, organization of a compiled plan for probable disasters, teaching, up to dating emergency check lists, creation of channels for responding to the people....

As studied, this manuscript evaluated the relationship between structural and content dimensions of an organization with crisis communications preparedness in the city departments of the Fars Province. In the future, it is recommended that researchers in addition to measuring high relations in the organization and other sections, to evaluate the relationship between environmental dimensions of an organization with crisis communications preparedness. 


\section{References}

[In Persian]

Daffet, Richard L (2009). Theory and organization design (Translation: Ali Parsaian, Seyed Mohammad Erabi), cover 1. Tehran: Office of Cultural Research Publications.

Hosseini, Seyed Yaghoub; Damnabi Asl, Ana (2013). Evaluation of level of influence of strategic management on quality of crisis management quality: case study: rail transportation industries of the country. Journal of Crisis Management, no 2, autumn and winter 2012.

McCarty, Shaun (2002). Role of information in crisis management. A primer on understanding the bipolar axis of producer, consumer of information (Translation: Mohammad Reza Tajik). Center for Strategic Presidential Evaluations. Tehran: Farhange Gofteman.

Mirsepasi, Naser; Godarzvand Ghegini, Mehrdad (2003). Study of the relationship between the environment, organizational structure and organizational effectiveness of city departments and presentation of a proposed model. Journal of City Management, no14.

Nafari, Neda; Omidfard, Gholamreza (2010). Evaluation of the level of structural effect (structural dimensions) on employee empowerment: case study deputy of expenses department of economy and assets. Journal of Process of Management and Development, no 73.

Nouri, Esmat (2011). Study of level of preparedness of crisis communications among organizations of the county of Kerman. MS Dissertation, Shahid Bahonar University, Kerman.

Rabii, Ali; Shaghasemi, Ehsan (2008). Crisis communications. Farasoo Journal, no3.

Rezaiian, Ali (2007). Management principles. Tehran: Samt Publications.

Robbins, Stephen (2007). Organizational theory, structure, design and applications (Translation: Seyed Mahdi Alvani and Hassan Danaiifard). Tehran: Eshraghi-Safar Publications.

Tajik, Mohammad Reza (2000). Crisis management. Tehran: Farhange Gofteman Publications.

Yazdi, Mahdi (2007). Role of culture in crisis management in the Golestan Province. Second National Conference of Renovation and [In Latin] Strengthening of Iran, Kerman, December 24 and 25, 2007.

Barnett, C. k. ;Pratt, M. G.(2000), From threat-rigidity to flexibility toward a learning model of autogenic crisis in organizations, journal of organizational change management,pp.74-88.

Borda, J. L., \& Mackey-Kallis, S. (2004), A model for crisis management, Hillsdale, NJ: Lawrence Erlbaum Associates, pp.117-137.

Campbell, R. (1999), Crisis control, Sydney: Prentice Hall.

Caponigro, J. R. (2000), The crisis counselor: A step-by-step guide to managing a business crisis, Chicago: Contemporary Books.

Carmeli,A., Schaubroeck,J(2008), organization crisispreparedness the important of learning from failures, long range planning, pp.177196.

Caywood, C., \& Stocker, K. P. (1993), The ultimate crisis plan, In J. A. Gottschalk (Ed.), Crisis response, Inside stories on managing image under siege, Detroit: Visible Ink, pp.409-428.

Cloudman, R.; Hallahan, K.(2006), Crisis communications preparedness among U.S. organizations: Activities and assessments by public relations practitioners, Public Relations Review, 32, 367-376.

Conrad, C., \& Pool, M. S. (2002), Strategic organizational communication in a global economy, Sydney: Wadsworth.

Drabek, T. (2003), Strategies for Coordinating Disaster Response, Institute of Behavioral Science, University of Colorado, Boulder, CO.

Engel, H. M. (1983), How to delegate: A guide to getting things done, Houston: Gulf Publishing Company.

Johnson, S. , and Scholes, K., (19^^) Exploring Corporate Stretegy. London. Prentice-Hall.

Heath,R. L.,\&Millar,D. P. (2004), Arhetorical approach to crisis communications: Management, communication processes, and strategic responses, Hillsdale, NJ: Lawrence Erlbaum Associates, pp.1-17.

Hurt, Kevin J; Abebe, Michel A, (2015), The Effect of Conflict Type and Organizational Crisis on Perceived Strategic Decision Effectiveness: An Empirical Investigation, Journal of Leadership \& Organizational Studies, Vol. 22(3) 340 -354.

Guth, D. W. (1995), Organizational crisis experience and public relations roles, Public Relations Review, 21(2), pp.123-137.

Guntzburger, Yoann; Pauchant Thierry C, (2014), Complexity and ethical crisis management, A systemic analysis of the Fukushima Daiichi nuclear disaster, Journal of Organizational Effectiveness: People and Performance, Vol. 1 No. 4, 2014, pp. 378-401.

Goby, Valerie P; Nickerson, Catherine, (2014), The impact of culture on the construal of organizational crisis: perceptions of crisis in Dubai, Corporate Communications: An International Journal, Vol. 20 No. 3, 2015, pp. 310-325.

Goodman, M. B. (1998), corporate communications for executives, New York: State University of New York Press.

Littlejohn, R. F. (1983), Crisis management: A team approach, New York: AMA Publications.

Lukaszewski, J. E. (1987), Checklist: Anatomy of a crisis response, Public Relations Journal, 43(11), p.45, 47.

Marra, F. J. (1998), Crisis communication plans: Poor predictors of excellent crisis public relations, Public Relations Review, 24(4), pp.461-474.

Marra, F. J. (2004), Excellent crisis communication: Beyond crisis plans, In R. L. Heath, \& D. P. Millar (Eds.), Responding to crisis: A thetorical approach to crisis communication, Hillsdale, NJ: Lawrence Erlbaum Associates, pp.311-325.

Middleberg, D. (2001), Winning PR in the wired world, New York: McGraw-Hill.

Nilsson, G. (1998), "Process orientation, integration of work teams and management control", Proceedings of the 4th International Seminar on Manufacturing Accounting Research, June 10-12, Kolding, Denmark.

Olson, Kva-Karin, (2014), Crisis Communication in Public Organisations: Dimensions of Crisis Communication Revisited, Journal of 
Contingencies and Crisis Management, Volume 22 Number 2 June 2014.

Penrose, J. M. (2000), The role of perception in crisis planning, Public Relations Review, 26 (2), pp. 155-171.

Preble, J. F. (1997), integrates the crisis management perspective with the strategic management process. Journal of Management Studies, 34 (5), 769-791.

Ritchie, B. W. (2004), Chaos, crisis and disasters: a strategic approach to crisis management in the tourism industry. Tourism Management, 25, 669 - 683.

Simon, H. A.( 1991), Bounded Rationality and Organizational Learning, Organizational Science, 1, PP. 125-134.

Sikich, W. G.(2004), All hazards crisis management, Logical Management.

Stacks, D. W. (2004), Crisis management: Toward a multidimensional model of public relations. In R. L. Heath, \& D. P. Millar (Eds.), Responding to crisis: A rhetorical approach to crisis communication, Hillsdale, NJ: Lawrence Erlbaum Associates, pp.37-49. 